\title{
SISTEM KONTROL ROBOT PENYEIMBANG BERBASIS ARDUINO MENGGUNAKAN METODE PID DENGAN KOMUNIKASI BLUETOOTH HC-05
}

\author{
Andi Chairunnas, Triyoga Ginanjar Pamungkas \\ Program Studi IImu Komputer - FMIPA Universitas Pakuan \\ Jl. Pakuan PO BOX 452, Bogor \\ Telp/Fax (0251) 8375547 \\ Email: andichairunnas@unpak.ac.id, triyoga.ginanjar.065114024@unpak.ac.id
}

\begin{abstract}
Abstrak
Penelitian ini membahas tentang sistem kontrol robot penyeimbang berbasis Arduino menggunakan metode pid dengan komunikasi bluetooth hc-05. Software yang di gunakan adalah Arduino IDE. Alat yang di gunakan pada sistem ini yaitu Arduino uno, MPU6050, drivermotor, bluetooth hc-05. Sistem ini berjalan berdasarkan inputan dari sensor MPU6050 yang digunakan untuk mendapatkan nilai tengah pada sebuah keseimbangan robot, Jika nilai keseimbangan tidak sama dengan nilai tengah maka motor robot akan bergerak dan berusaha untuk menyeimbangkan robot. Dan pada sistem ini di kontrol menggunakan bluetooth hc-05 sebagai mengontrol nilai tengah dan menetapkan nilai tengah.
\end{abstract}

Kata Kunci: MPU6050, Balancing robot, Mikrokontroler, Arduino, Robot

Abstract
This research proposes self-balancing robot control systems with arduino using pid methods and bluetooth hc-05 to communicate. The software that is used for this system is Arduino IDE. The equipments that is used are Arduino uno, mpu6050, drivermotor, and bluetooth hc-05. This system works based on mpu6050 input signals to get a median in selfbalancing robot, if the balance value is not equal to the median then the robot motors will move and try to balance the robot. This system is controlled by bluetooth hc-05 to control and determine the median.

Keyword : MPU6050, Balancing robot, Mikrokontroler, Arduino, Robot

Keywords : MPU6050, Balancing robot, Mikrokontroler, Arduino, Robot

\section{Pendahuluan}

Perkembangan robotika di tanah air selama beberapa tahun terakhir ini terus mengalami peningkatan. Peserta lomba robot yang secara tetap diadakan tiap tahun mulai bertambah khususnya dikalangan mahasiswa. Di tingkat nasional ada Kontes Robot Cerdas Indonesia yang diselenggarakan oleh Direktor Perguruan Tinggi Indonesia dan pada tingkat internasional ada ROBOCON. Ternyata perkembangan robotika tidak hanya di kalangan mahasiswa, tetapi juga pada kalangan SD, SMP maupun SMA. Robot yang digunakan adalah LEGO ROBOTIC yaitu sebuah produk lego yang bisa dirangkai menjadi sebuah robot dan dapat diprogram dari komputer. LEGO ROBOTIC ini memadukan kemampuan mekanika dan kemampuan programming untuk memecahkan berbagai masalah.

Melihat keadaan ini, memperkenalkan pada khalayak bahwa robot juga bisa digunakan seperti simulasi atau prototype untuk dilakukan perancangan dan penganalisaan. Contoh sederhana yang dapat disimulasikan dengan robot adalah Robot balancing atau robot penyeimbang merupakan robot beroda dua yang dapat menyeimbangkan diri. Saat ini kebanyakkan sistem keseimbangan telah diterapkan pada robot yang dapat mengudara, tetapi sedikit yang diterapkan pada robot di daratan. Untuk mengatasi serta memperluas perkembangan teknologi robotik di daratan tersebut, maka penulis berinisiatif untuk merancang 
sebuah robot yang dapat menyeimbangkan diri dan dapat dikendalikan dengan smartphone android melalui bluetooth sebagai penghubung. Serta akan muncul cara baru dari kemampuan bermanuver dan mobilitas dalam aplikasi robotik di daratan, sehingga dapat menjadi acuan dalam perkembangan sistem transportasi yang ramah lingkungan dan modern.

Penelitian sebelumnya [5] menerangkan kestabilan pada robot dikendalikan dengan metode kendali PID, yang merupakan sistem pengendali yang berfungsi untuk mencari nilai kestabilan sehingga respon sistem yang diperoleh dapat mencapai setpoint. Maka dari itu diperlukan sistem penyeimbang yang dapat membaca sudut kemiringan pada robot. Pembacaan sudut tersebut akan menjadi acuan putaran pada roda.

Konsep robot penyeimbang didasarkan pada teori pendulum terbalik. Sebuah sistem kontrol yang sesuai dibutuhkan untuk mengontrol sistem sehingga seimbang dan stabil. Tujuan utama dari perancangan robot ini adalah untuk menjaga robot dalam keadaan tegak lurus. Meskipun di dunia robotika Robot Balancing sudah banyak dikenal, namun masih banyak yang dapat ditambahkan pada robot penyeimbang ini, dikarenakan saat ini robot penyeimbang hanya dibuat ada yang tanpa sensor jarak akan tetapi sudah menggunakan sistem android sebagai pengontrolnya dan ada juga robot penyeimbang yang dibuat dengan menggunakan sensor jarak akan tetapi tidak berbasis android. Berdasarkan latar belakang di atas maka penulis akan mengangkat sebuah judul "Sistem Kontrol Robot Penyeimbang Berbasis Arduino Menggunakan Metode PID Dengan Komunikasi Bluetooth Hc-05".

Dengan tujuan untuk merancang robot berbasis mikrokontroler yang dapat menyeimbangkan diri dan menghindari objek, melakukan analisa kendali motor berdasarkan data sensor, robot yang dapat membaca data dari sensor untuk menyeimbangkan diri, untuk mengetahui prinsip kerja secara umum dari sistem robot penyeimbangan yang di rancang.

Tujuan dari penelitian ini untuk merancang robot berbasis mikrokontroler yang dapat menyeimbangkan diri dan menghindari objek, melakukan analisa kendali motor berdasarkan data sensor, robot yang dapat membaca data dari sensor untuk menyeimbangkan diri, untuk mengetahui prinsip kerja secara umum dari sistem robot penyeimbangan yang dirancang, dan melakukan analisa dari hasil pengujian.

Ruang lingkup dalam laporan penelitian ini dibatasi pada ukuran range sudut yang di gunakan $-5^{\circ}$ sampai dengan $5^{\circ}$, serta menggunakan kecepatan $10 \mathrm{rpm}$. Komunikasi bluetooth menggunakan module bluetooth $\mathrm{HC}-05$ atau sejenisnya dengan jarak robot dan kontroler maksium 10 meter, perancangan ini menggunakan mikrokontroler Arduino, arduino yang digunakan adalah Arduino UNO R3 atau Arduino yang dirancang sendiri (handmade) atau sejenisnya, dan software yang digunakan adalah Arduino IDE sebagai pemrograman bahasa $\mathrm{C}$ untuk mikrokontroler.

Manfaat dari penelitian ini diharapkan dapat memberikan manfaat dapat menambah wawasan dalam bidang mikrokontroller dalam membantu permasalahan yang lebih baik menggunakan mikrokontrolle dan menjadi referensi dan menambah wawasan pengetahuan tentang penerapan aplikasi mikrokontroller dalam membantu pekerjaan menjadi lebih mudah dan efisien.

Sistem Kontrol adalah sebuah cara dimana kita mencoba mengontrol, mengorganisir dan memanfaatkan sesuatu dengan sebuah controller yang dibuat dengan menggunakan perangkat keras yang dipakai agar robot tersebut bekerja sesuai yang kita inginkan selaku user. Sistem kontrol juga pada umumnya memiliki beberapa jenis mulai dari Open Loop Control, Closed Loop Control, Self Regulation dan Feed Forward Control. Seiring berkembangnya teknologi, sistem kontrol banyak diterapkan dibidang apa saja termasuk dibidang robotika. Sistem kontrol dibidang robotika juga banyak cara penerapannya bisa dengan joystick, wireless, Short Message System (SMS) dan sensor yang memang diperuntunkan untuk sistem kontrol (Nugra, 2013).

Sistem kontrol juga merupakan suatu kumpulan cara atau metode yang dipelajari dari kebiasaan-kebiasaan manusia dalam bekerja, manusia membutuhkan suatu pengamatan kualitas dari apa yang telah mereka kerjakan sehingga memiliki karakteristik sesuai dengan yang diharapkan. Perkembangan teknologi menyebabkan manusia selalu terus belajar untuk mengembangkan dan mengotimalkan pekerjaan-pekerjaan kontrol yang semula dilakukan oleh manusia menjadi serba otomatis [6]. 
MPU 6050 adalah chip IC invense yang di dalamnya terdapat sensor accelerometer dan Gyroscope yang sudah terintegrasi. Alasan menggunakansensor ini adalah karena harganya relatif murah dimana sudah mendapatkan 2 sensor yang sudah terintegrasi.

Prinsip kerja dari MPU6050 ketika gyroscope bergerak maka akan menghasilkan tegangan output. Pada saat gyroscope diam maka tegangan akan konstan. Ketika gyroscope berputar searah jarum jam terhadap sumbu Z maka tegangan ouput berkurang (- Z), dan ketika gyroscope berputar berlawanan arah jarum jam maka tegangan output bertambah (+ Z).Sensor giroskop MEMS (microelectromechanical) berukuran kecil (antara 1 sampai 100 mikrometer, ukuran rambut manusia). Ketika gyroscope diputar, massa beresonansi kecil digeser sebagai perubahan kecepatan sudut. Gerakan ini diubah menjadi sinyal-sinyal listrik yang sangat kecil yang kemudian dinaikkan nilainya sehingga bisa terbaca oleh mikrokontroller.

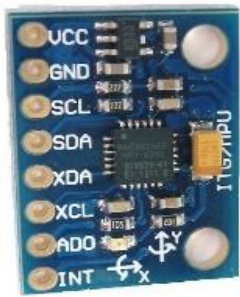

Gambar 1. Modul GY 521 MPU-6050

Arduino Uno R3 adalah papan mikrokontroler berdasarkan ATMEGA8. Arduino ini memiliki 14 digital input / output pin (dimana 6 dapat digunakan sebagai output PWM), 6 input analog, osillator kristal $16 \mathrm{MHz}$, koneksi USB, jack DC, header ICSP, dan tombol reset. Board ini berisi semua yang diperlukanuntuk mendukung mikrokontroler, cukup menghubungkannya ke komputer dengan kabel USB atau kekuasaan itu dengan adaptor AC-DC atau baterai untuk memulai. Arduino Uno R3 berbeda dari semua papan sebelumnya yang tidak menggunakan chip FTDI driver USB-to-serial. Sebaliknya, Arduino ini memiliki fitur Atmega16U2 (Atmega8U2 hingga versi R2) diprogram serial.

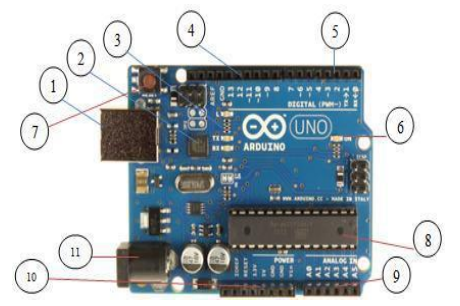
sebagai konverter USB-to-

\section{Gambar 2. Arduino Uno R3}

Sistem Bluetooth terdiri dari sebuah radio transceiver, baseband linkManagement dan Control, Baseband (processor core, SRAM, UART, PCM USB Interface), flash dan voice code. sebuah link manager. Baseband link controller menghubungkan perangkat keras radio ke baseband processing dan layer protocol fisik. Link manager melakukan aktivitas-aktivitas protokol tingkat tinggi seperti melakukan link setup, autentikasi dan konfigurasi. Bentuk fisik modul Bluetooth $\mathrm{HC}-06$ dapat dilihat

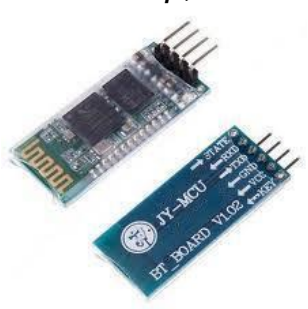
pada Gambar 3 di bawah ini. 
Gambar 3. Bentuk Fisik Modul Bluetooth HC-06 dan HC-05

Motor DC atau motor listrik yang dimana dia memerlukan suplai tegangan arus searah pada kumparan medan untuk dirubah menjadi energi gerak mekanik. Energi mekanik ini digunakan untuk memutar impeller pompa, fan atau blower, menggerakkan kompresor, mengangkat bahan, dan lain-lain. Kumparan medan pada motor dc disebut stator (bagian yang tidak berputar) dan kumparan jangkar disebut rotor (bagian yang berputar) dan biasanya motor dc digunakan pada penggunaan khusus dimana diperlukan penyalaan torque yang tinggi atau percepatan yang tetap untuk kisaran kecepatan yang luas [2].

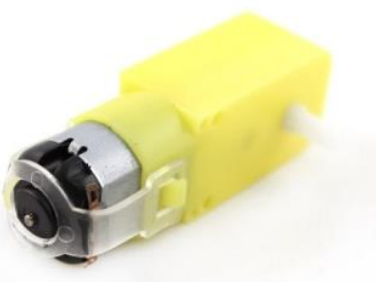

Gambar 4. Motor DC

2. Metode Penelitian

Metode penelitian yang digunakan untuk mengembangkan penelitian ini adalah metode penelitian bidang hardware programing yang ditunjukkan pada Gambar 5.

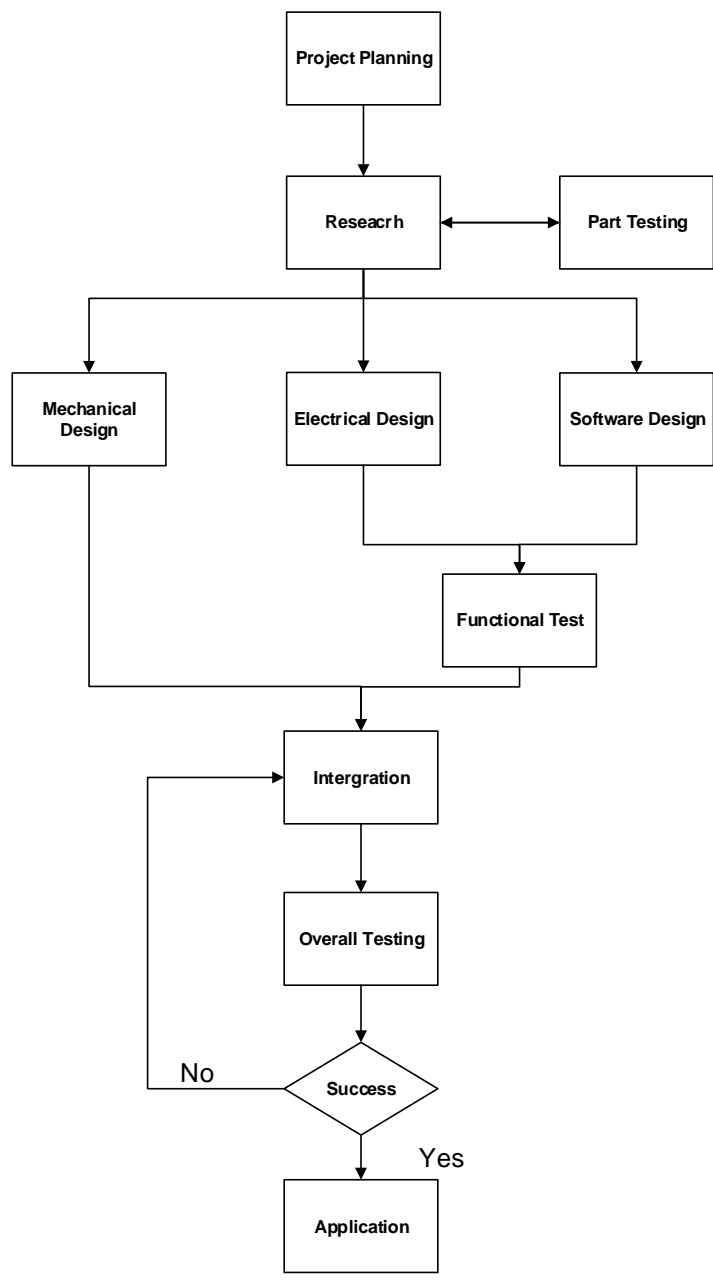




\section{Gambar 5. Metode Penelitian Hardware Programing}

\subsection{Perencanaan Rancangan Penelitian (Project Planning)}

Dalam perencanaan proyek penelitian, terdapat beberapa hal penting yang harus ditentukan dan dipertimbangkan, antara lain:

1. Penentuan topik dan kerangka awal penelitian

2. Estimasi kebutuhan alat dan bahan

3. Estimasi anggaran

4. Perangkat lain, dan

5. Kemungkinan penerapan dari hardware yang akan dirancang

\subsection{Penelitian (Research)}

Setelah perencanaan yang dilakukan telah matang, maka dilanjutkan penelitian awal dari hardware yang akan dibuat, dimulai dari pemilihan dan pengetesan komponen (alat dan bahan), kemungkinan dari rancangan awal maupun akhir dari hardware yang akan dilakukan yaitu "Sistem Kontrol Robot Penyeimbang Berbasis Arduino Menggunakan Metode PID dengan Kompunikas Bluetooth HC-05".

\subsection{Pengetesan Komponen (Parts Testing)}

Pada proses ini dilakukan pengetesan pada alat-alat yang akan digunakan sesuai kebutuhan dari aplikasi yang sebelumnya sudah didesain.

\subsection{Desain Sistem Mekanik (Mechanical Design)}

Proses perancangan mekanik merupakan hal penting yang harus dipertimbangkan dalam pengembangan hardware. Pada umumnya kebutuhan aplikasi terhadap desain mekanik antara lain :

1. Bentuk dan ukuran akrilik

2. Ketahanan dan fleksibilitas terhadap lingkungan

3. Penempatan modul-modul elektronik

4. Pengetesan system mekanik yang telah di rancang

5. Bentuk desain ukuran interface hardware

\subsection{Desain Sistem Listrik (Electrical Design)}

Sebelum merancang desain sistem listrik terdapat beberapa hal yang harus diperhatikan, antara lain:

1. Sumber catu daya dan pembagian daya untuk masing-masing komponen

2. Kontroller yang akan digunakan

3. Kebutuhan tegangan dan arus untuk mikrokontroler, sensor dan aktuator

4. Desain driver untuk pendukung aplikasi

5. Desain sistem kontrol yang akan diterapkan

6. Pengetesan sistem listrik yang telah dirancang

7. Flowchart perancangan sistem robot

\subsection{DesainPerangkat Lunak (Software Testing)}

Dalam proses ini, perangkat lunak yang dibutuhkan adalah Arduino IDE, Ms. Visio, Ms. Word, Fritzing, dan Google SketchUp.

\subsection{Tes Fungsional}

Tahap tes fungsional meliputi pengetesan fungsional sistem yang telah terintegrasi antara desain listrik dan desain perangkat lunak agar meningkatkan performa dan mengeliminasi error (bug) yang ada.

\subsection{Integrasi atau Perakitan}

Modul listrik yang diintegrasi dengan software di dalam kontrollernya, diitegrasikan dalam struktur mekanik yang telah dirancang. Lalu dilakukan tes fungsional keseluruhan sistem. 


\subsection{Tes Fungsional Keseluruhan Sistem}

Dilakukan pengetesan fungsi dari keseluruhan sistem, dalam tahap ini kita mencoba apakah sistem dapat berfungsi sesuai dengan konsep atau tidak. Jika dalam tahap tes ini terdapat sistem yang tidak sesuai dengan konsep maka harus dilakukan proses perakitan ulang pada setiap desain sistemnya.

\subsection{Aplikasi (Application)}

Application dilakukan untuk meningkatkan performa dari aplikasi yang telah dirancang. Application ditekankan pada desain mekanik agar penggunaan lebih maksimal serta optimal.

\subsection{Perancangan dan Implementasi}

Pada perencanaan rancangan penelitian ini dibutuhkan perencanaan arsitektur dengan menggunakan sensor mpu-6050 yang kemudian tersambung dengan mikrokontroler arduino untuk diproses mendapatkan sudut dan kecepatan, lalu data yang telah diproses oleh arduino akan di olah dengan perhitungan PID untuk dikirimkan berupa perintah-perintah ke motor dc melalui motor driver I298n, perintah tersebut akan dikirimkan ke motor dc untuk untuk mengatur nilai sudut untuk keseimbangan apa yang sesuai data yang didapatkan.

Setelah melewati proses perencanaan, proses selanjutnya yaitu penelitian awal dari aplikasi yang akan dibuat dimulai dari merancang rangkaian mekanik serta komponen dari model sistem kontrol dan model robot untuk memastikan bahwa semua komponen berjalan dengan optimal. Model sistem kontrol ini menggunakan papan Arduino Uno sebagai otak dari sistem kontrol yang akan mengatur manuver-manuver sebagai output dari robot. Input dari model ini adalah data yang didapat dari mpu-6050 biasanya didapat dengan cara memiringkan sensor tersebut sehingga mendapatkan nilai sudut kemiringan. Robot telah diberikan perintah untuk mengeksekusi manuver sesuai perintah yang telah diberikan oleh mikrokontroller arduino.

Pada tahap ini dilakukan pengetesan komponen-komponen yang akan digunakan menggunakan multimeter. Pengetesan menggunakan Arduino serial monitoring dilakukan dengan melihat output tiap komponen dan sensor yang terhubung dengan Arduino melalui koneksi USB. Pengujian menggunakan multimeter meliputi pengujian tegangan input dan output setiap komponen. Desain mekanik robotnya dapat dilihat pada Gambar 6 berikut. 


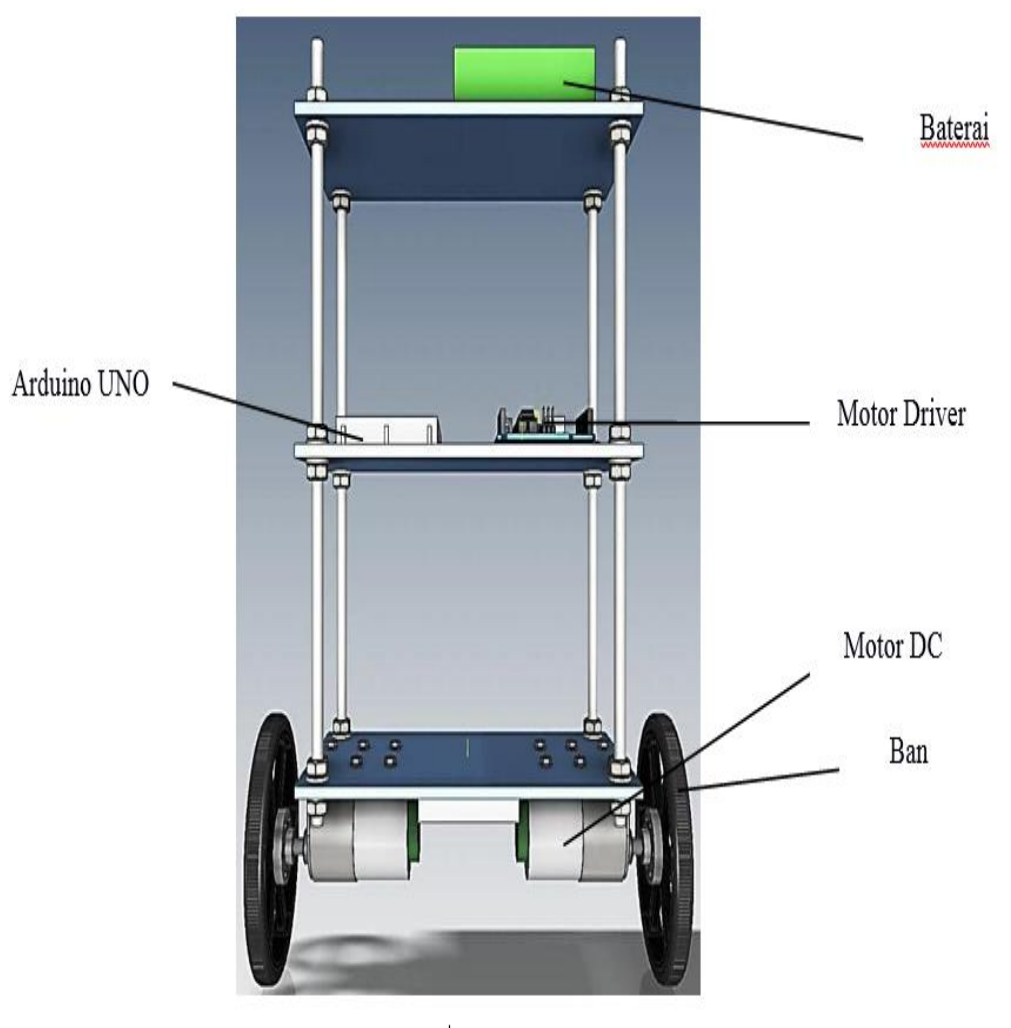

Gambar 6. Perancangan Sistem Mekanik Robot

Perancangan skematik rangkaian menggunakan perangkat lunak Fritzing berdasarkan diagram blok pada Gambar 7 berikut.

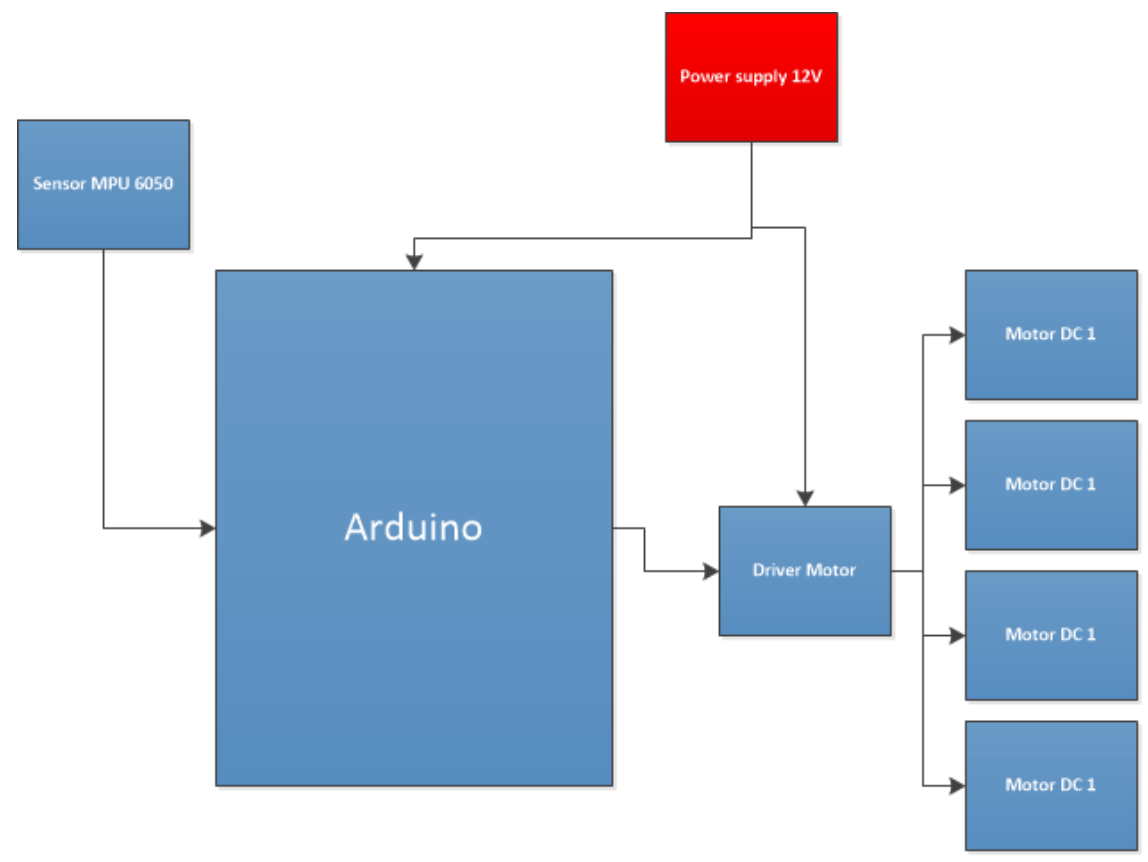

Gambar 7. Diagram Blok 


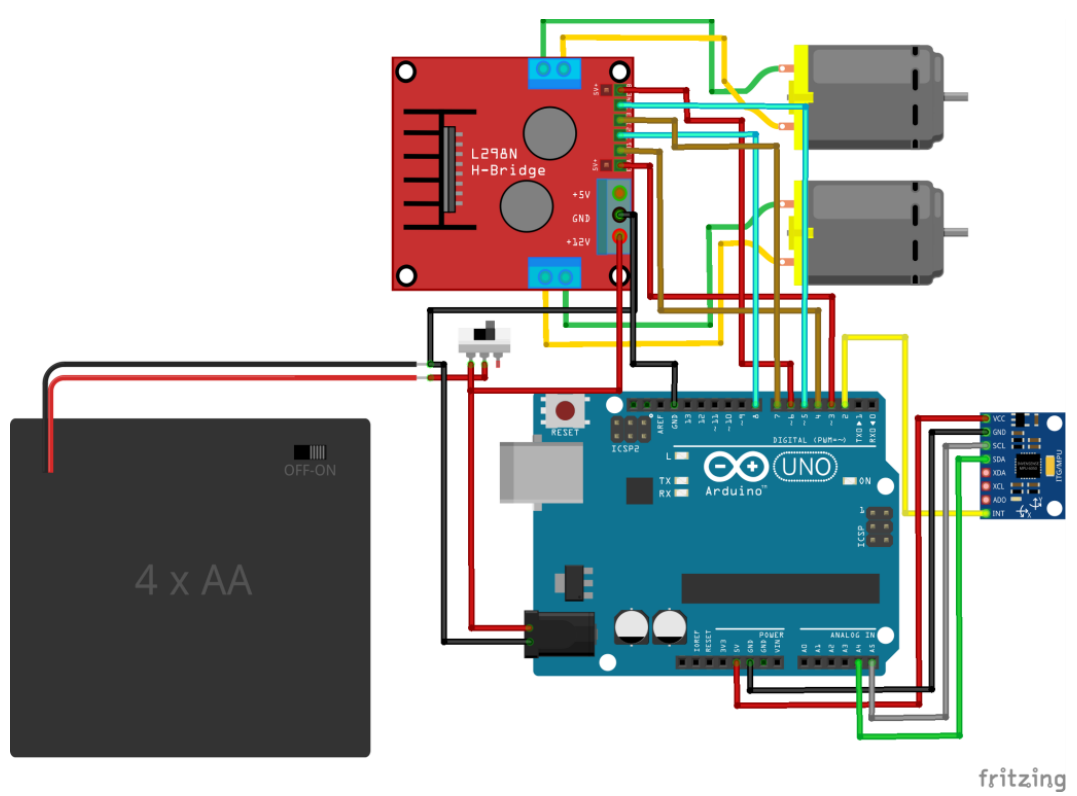

Gambar 8. Skematik Rangkaian Robot Penyeimbang

Sumber tegangan menggunakan catu daya $12 \mathrm{~V}$ yang akan menyuplai arus ke Arduino dan driver motor. Arus catu daya yang dialirkan ke arduino akan dialirkan kembali ke komponenkomponen seperti mpu-6050 dan Bluetooth HC-06/05. Pada mpu-6050 terdapat 3 output yang disambungkan dengan arduino yaitu SDA pada pin A4, SCL pada pin A5 dan INT pada pin 2. Kemudian masing- masing pin ground dihubungkan dengan pin ground Arduino.

Proses desain perangkat lunak sistem ini dibuat dengan Bahasa Pemrograman $\mathrm{C}$ pada arduino uno berdasarkan flowchart pada Gambar 9 berikut.

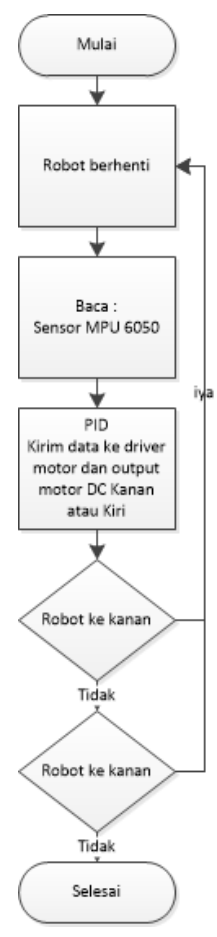

Gambar 9. Flowchart Sistem Kontrol 
Setelah melakukan perancangan perangkat lunak kemudian dilakukan tes fungsional. Tes ini dilakukan untuk meningkatkan kinerja dari perangkat lunak dalam mengontrol perancangan desain listrik. Selain itu bertujuan untuk mengantisipasi adanya errordari perangkat lunak yang dibuat. Apabila software telah selesai diuji maka masuk ke proses perakitan. Proses perakitan ini dilakukan berdasarkan proses dari desain baik desain mekanik, elektronik maupun desain perangkat lunak.

\section{Hasil dan Pembahasan}

3.1 Hasil Penelitian

Model robot balancing dibuat dari bahan akrilik dengan tebal $3 \mathrm{~mm}$, tinggi $10 \mathrm{~cm}$, lebar $7 \mathrm{~cm}$ dan panjang $17 \mathrm{~cm}$. Pada robot balancing, arduino uno dihubungkan dengan sensor mpu6050 untuk mendapatkan sumbe $\mathrm{Y}$ kemiringan dan arduino uno diset dengan motordriver yang terhubung dengan 2 buah motor dc.

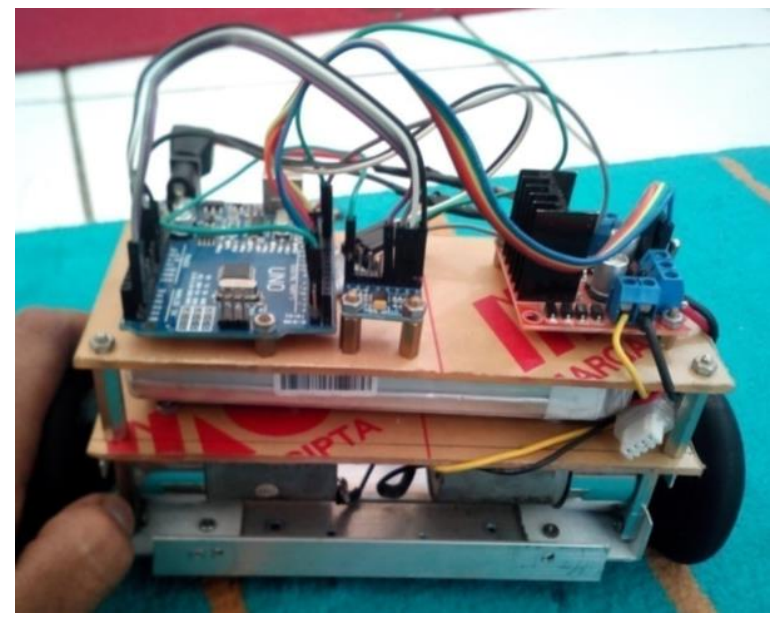

Gambar 10. Keseluruhan Sistem

\subsection{Test Fungsional Keseluruhan Sistem (Overall Testing)}

Dalam tahap ini dilakukan pengetesan fungsi dari keseluruhan sistem. Apakah dapat berfungsi sesuai dengan konsep atau tidak. Jika ada sistem yang tidak dapat bekerja dengan baik, maka harus dilakukan proses perakitan ulang setiap bagian sistemnya. Pengujian ini meliputi pengujian struktural, fungsional dan validasi.

\subsubsection{Pengujian Struktural}

Tahap pengujian struktural ini dilakukan untuk mengetahui apakah jalur-jalur rangkaian sudah terhubung dengan benar sehingga sistem dapat berjalan berfungsi dengan baik. Pengujian ini dilakukan dengan mengetes jalur-jalur rangkaian menggunakan multimeter dan juga adaptor. Berikut tabel hasil pengujian struktural sistem.

Tabel 1. Pengujian Struktural

\begin{tabular}{|c|c|c|c|c|}
\hline No & \multicolumn{2}{|c|}{ Komponen Sistem } & Terhubung dengan & Keterangan \\
\hline \multirow{2}{*}{1} & \multirow{2}{*}{$\begin{array}{c}\text { Arduino Uno } \\
\text { pada robot } \\
\text { balancing }\end{array}$} & Mpu-6050 & $\begin{array}{l}\text { SDA, SCL, INT, } \\
\text { VCC, GND }\end{array}$ & Terhubung \\
\hline & & Motordrive L298D & $\begin{array}{c}\text { Ena, Enb, In } 1, \ln 2, \\
\ln 3, \ln 4, \text { GND }\end{array}$ & Terhubung \\
\hline 2 & $\begin{array}{l}\text { Motor Drive } \\
\text { L298D }\end{array}$ & Motor DC & $\begin{array}{l}\text { Socket M1, M2, } \\
\text { M3, M4 }\end{array}$ & Terhubung \\
\hline
\end{tabular}

Komputasi Vol. 15, No. 2, Juli 2018 : 140 - 194 
Pada tahap ini dilakukan pengujian yang bertujuan untuk mengetahui apakah tegangan yang mengalir di dalam rangkaian sudah sesuai dengan yang dibutuhkan. Pengujian ini dilakukan dengan cara mengetes tegangan output tiap komponen dengan menggunakan multimeter maupun program.

3.2.3 Uji Coba Validasi

Tahap ini dilakukan dengan melakukan pengujian sumbu $Y$ pada sensor mpu-6050, kecepatan motor, jari-jari ban, serta ketinggian robot.

1. Pengujian sumbu $Y$ sensor mpu-6050

Tabel 2. Pengujian sumbu $Y$ sensor mpu-6050

\begin{tabular}{|c|c|c|c|c|}
\hline No & Nilai sumbu $Y$ & $\begin{array}{c}\text { Nilai Titik } \\
\text { Tengah }\end{array}$ & $\begin{array}{l}\text { Kondisi motor } \\
\text { DC }\end{array}$ & Keterangan \\
\hline 1 & 183.56 & \multirow{10}{*}{181.81} & CW & Valid \\
\hline 2 & 183.28 & & CW & Valid \\
\hline 3 & 182.68 & & CW & Valid \\
\hline 4 & 182.18 & & CW & Valid \\
\hline 5 & 181.93 & & CW & Valid \\
\hline 6 & 181.81 & & Berhenti & Valid \\
\hline 7 & 181.74 & & CCW & Valid \\
\hline 8 & 181.67 & & CCW & Valid \\
\hline 9 & 181.28 & & $\mathrm{CCW}$ & Valid \\
\hline 10 & 181.17 & & CCW & Valid \\
\hline
\end{tabular}

2. Pengujian sudut $Y\left({ }^{\circ}\right)$ sensor mpu-6050

Tabel 6. Pengujian sudut $Y\left(^{\circ}\right)$ sensor mpu-6050

\begin{tabular}{|c|c|c|c|c|c|}
\hline No & $\begin{array}{l}\text { Nilai sudut } \\
Y\left({ }^{\circ}\right)-180^{\circ}\end{array}$ & $\begin{array}{c}\text { Nilai Titik } \\
\text { Tengah }\end{array}$ & $\begin{array}{l}\text { Hasil Sudut } \\
\text { yang di } \\
\text { dapatkan }\end{array}$ & $\begin{array}{l}\text { Kondisi motor } \\
\text { DC }\end{array}$ & Keterangan \\
\hline 1 & 183.56 & \multirow{10}{*}{181.81} & +1.75 & CW & Valid \\
\hline 2 & 183.28 & & +1.47 & CW & Valid \\
\hline 3 & 182.68 & & +0.87 & CW & Valid \\
\hline 4 & 182.18 & & +0.37 & CW & Valid \\
\hline 5 & 181.93 & & +0.12 & CW & Valid \\
\hline 6 & 181.81 & & 0 & Berhenti & Valid \\
\hline 7 & 181.74 & & -0.07 & CCW & Valid \\
\hline 8 & 181.67 & & -0.14 & CCW & Valid \\
\hline 9 & 181.28 & & -0.53 & CCW & Valid \\
\hline 10 & 181.17 & & -0.64 & CCW & Valid \\
\hline
\end{tabular}

3. Pengujian Ukuran Ban

Tabel 7. Pengujian ukuran ban

\begin{tabular}{|c|c|c|}
\hline No & Ukuran jari-jari & Kondisi robot \\
\hline 1 & $10.5 \mathrm{~cm}$ & Stabil bergerak \\
\hline 2 & $5 \mathrm{~cm}$ & Stabil bergerak \\
\hline
\end{tabular}

4. Pengujian Tinggi Robot

Tabel 8. Pengujian tinggi robot

\begin{tabular}{|c|c|c|}
\hline No & Ukuran tinggi & Kondisi robot \\
\hline 1 & $25 \mathrm{~cm}$ & Bergerak tidak stabil \\
\hline 2 & $10 \mathrm{~cm}$ & Stabil bergerak \\
\hline
\end{tabular}

5. Pengujian Kecepatan Robot

Tabel 9. Pengujian kecepatan robot

\begin{tabular}{|c|c|c|}
\hline No & Kecepatan robot & Kondisi robot \\
\hline 1 & $3 \mathrm{rpm}$ & Bergerak stabil \\
\hline 2 & $5 \mathrm{rpm}$ & Bergerak stabil \\
\hline 3 & $8 \mathrm{rpm}$ & Bergerak stabil \\
\hline
\end{tabular}

Sistem Kontrol Robot Penyeimbang Berbasis Arduino Menggunakan Metode PID dengan Komunikasi Bluetooth HC-5 (Andi Chairunnas) 


\begin{tabular}{|c|c|c|}
\hline 4 & $10 \mathrm{rpm}$ & Bergerak stabil \\
\hline 5 & $13 \mathrm{rpm}$ & Bergerak stabil \\
\hline
\end{tabular}

Dari hasil uji coba yang saya lakukan, pada sensor mpu-6050 saya menggunakan sumbu $Y$ pada sensor tersebut. Dengan nilai sudut yang akan dihasilkan sebesar maksimal $5^{\circ}$ dan minimal $-5^{\circ}$. Nilai tersebut di tambahkan dengan nilai maksimal dari sumbu yaitu $180^{\circ}$, Contohnya nilai sumbu tersebut $1,23^{\circ}$ dan nilai tersebut akan di tambahkan nilai sumbu maksimal yaitu $180^{\circ}$ maka nilai perhitungan nya akan menjadi $181,23^{\circ}$. Jika sudah mendapatkan nilai tersebut akan di bandingkan dengan nilai titik tengah yang sudah di tentukan sebelumnya yaitu $181,81^{\circ}$, jika nilai sensor lebih kecil dari sumbu maksimal maka motor dc akan bergerak berlawanan arah jam atau CCW(Counter Clock Wise) sebaliknya jika nilai sensor lebih besar dari sumbu maksimal maka motor dc akan bergerak searah jam atau CW (Counter Wise). Untuk ukuran jari-jari ban dan ukuran tinggi berpengaruh pada gerak pada robot tersebut. Semakim jari-jari ban besar maka gerak robot akan semakin pelan tetapi terlihat seimbang, tetapi jika jari-jari ban nya kecil maka gerak robot akan semakin cepat dan terlihat robot berusaha untuk seimbang. Untuk tinggi robot jika semakin tinggi robot tersebut maka semakin keseimbangan nya tidak stabil sebaliknya jika tinggi robot tidak lebih dari $12 \mathrm{~cm}$ maka robot terlihat seimbang.

\subsection{Optimisasi Sistem (Optimization)}

Pada model robot ini masih di temukan kendala dalam penentuan sudut yang di dapatkan dari sensor maka dapat dilakukan optimasi untuk meningkatkan perfoma dari model robot yang di rancang. Dalam perancangan selanjutnya dapat di kembangkan pada model robot ini khususnya pada penggunaan sensor agar mendapatkan sudut dan kecapatan yang sesuai, dengan kondisi kemiringan tertentu model robot ini masih tetap seimbang.

Dalam model robot ini masih di temukan kesalahan sistem dalam menentukan sudut kemiringan yang di peroleh dengan kondisi medan yang di terima sensor tersebut, harus adanya titik tengah agar kita mengetahui nilai maksimal sudut dan minimal sudut.

Tabel 10. Optimasi sudut kemiringan dengan kecapatan

\begin{tabular}{|c|c|c|c|}
\hline No & Kecepatan robot & $\begin{array}{c}\text { Sudut kemiringan } \\
\mathrm{Y}\left({ }^{\circ}\right.\end{array}$ & Kondisi robot \\
\hline 1 & $0 \mathrm{rpm}-100 \mathrm{rpm}$ & $-5^{\circ}-5^{\circ}$ & Bergerak stabil \\
\hline 2 & $150 \mathrm{rpm}-250 \mathrm{rpm}$ & $-5^{\circ}-5^{\circ}$ & Robot stabil tetapi bergetar \\
\hline 3 & $0 \mathrm{rpm}-100 \mathrm{rpm}$ & $-6^{\circ}-6^{\circ}$ & $\begin{array}{c}\text { Bergerak stabil tetapi tidak diam } \\
\text { ditempat }\end{array}$ \\
\hline 4 & $150 \mathrm{rpm}-250 \mathrm{rpm}$ & $-6^{\circ}-6^{\circ}$ & Robot tidak stabil \\
\hline 5 & $0 \mathrm{rpm}-100 \mathrm{rpm}$ & $-7^{\circ}-7^{\circ}$ & $\begin{array}{c}\text { Bergerak stabil tetapi tidak diam } \\
\text { ditempat }\end{array}$ \\
\hline 6 & $150 \mathrm{rpm}-250 \mathrm{rpm}$ & $-7^{\circ}-7^{\circ}$ & Robot tidak stabil \\
\hline 7 & $0 \mathrm{rpm}-100 \mathrm{rpm}$ & $-8^{\circ}-8^{\circ}$ & $\begin{array}{c}\text { Bergerak stabil tetapi tidak diam } \\
\text { ditempat }\end{array}$ \\
\hline 8 & $150 \mathrm{rpm}-250 \mathrm{rpm}$ & $-8^{\circ}-8^{\circ}$ & Robot tidak stabil \\
\hline 9 & $0 \mathrm{rpm}-100 \mathrm{rpm}$ & $-9^{\circ}-9^{\circ}$ & $\begin{array}{c}\text { Bergerak stabil tetapi tidak diam } \\
\text { ditempat }\end{array}$ \\
\hline 10 & $150 \mathrm{rpm}-250 \mathrm{rpm}$ & $-9^{\circ}-9^{\circ}$ & Robot tidak stabil \\
\hline
\end{tabular}

Berdasarkan pengujian yang telah dilakukan, secara umum model robot bergerak stabil diam di tempat pada kecepatan 0 - $100 \mathrm{rpm}$ lebih dari kecepatan tersebut maka robot akan bergerak stabil tetapi tidak diam ditempat. Untuk sudut kemiringan yang diuji dari 5 sampai 9 derajat jika lebih dari 9 maka robot bergerak semakin tidak stabil. Optimasi dilakukan untuk mengetahui seberapa jauh sudut kemiringan yang dapat di peroleh agar robot bergerak

Komputasi Vol. 15, No. 2, Juli 2018: $140-194$ 
seimbang yang dapat di pengaruhi oleh kecepatan motor serta kemungkinan terjadi adanya pengaruh dari luar.

\section{Kesimpulan}

Kesimpulan dari penelitian ini, model sistem control robot keseimbangan dengan menggunakan komunikasi Bluetooth hc-05. Sistem ini menggunakan papan Arduino Uno, driver motor, MPU 6050, Bluetooth hc-05, Motor DC. Input sistem ini berupa nilai sumbu y yang didapatkan dari sensor MPU 6050. Nilai yang diperoleh tersebut akan diproses oleh arduino untuk disesuaikan dengan perintah yang ada dan menggerkan motor dc untuk menyeimbangkan robot.

Model sistem kontrol robot beroda ini menggunakan komunikasi Bluetooth hc-05 ini perlu pengembangan lebih lanjut untuk meningkatkan fungsi dan fitur sistem seperti :

1. Penggunaan motor dc sangat boros, terutama jika kita menggunakan baterai yang mempunyai daya tampung yang kecil. Mungkin bisa menggunakan baterai on board yang lebih besar daya tampungnya tetapi ukuran baterainya yang sangat besar dan memakan tempat. Tapi lebih baik kita mencari motor dc yang menggunakan daya kecil.

2. Untuk menambah kelengkapannya kita bisa menggunakan kontrol jalan pada robot.

\section{References}

[1] Ansori, Wildan. Sistem Kontrol Robot Beroda Berbasis Mikrokontroller ATMega128 Menggunakan Speech Recognition Dengan Komunikasi Bluetooth Sebagai Transfer Data. Jurnal Skripsi. Jurusan Ilmu Komputer, Universitas Pakuan. 2014.

[2] David. "Electronics Hub." [Online]. Available: http://www.electronicshub.org/arduino-rotaryencoder/. [Accessed 20 Oktober 2017]. 18 Februari 2016.

[3] Gilang, Bayu. Robot Pemadam Api Dengan Sistem Pengontrol Kendali Jarak Jauh. Skripsi. Jurusan Ilmu Komputer, Universitas Pakuan. 2012.

[4] H. D. Laksono, "Wordpress," Maret 2011. [Online]. Available: https://herudibyolaksono.files.wordpress.com/2011/03/kestabilansistem-kendali.pdf. [Accessed 20 Oktober 2017].

[5] Novandri, Andri, Rosalidar \& Aulia Rahman. Rancang Bangun Robot Self Balancing Berbasis Mikrokontroler ATmega328P Dengan Kendali PID. Jurusan Teknik Elektro \& Komputer, Universitas Syiah Kuala. 2017.

[6] Sayyid, Abdul Rohman., Mada Sanjaya WS \& Yudha Satya P. Kontrol Mobil Robot Menggunakan Hand Gesture Recognition Dengan Metode Adaptive Neuro-Fuzzy Interference System (ANFIS). Journal of Physics. Vol.2 No.1. 2015.

[7] "Zona Elektro," 21 Oktober 2014. [Online]. Available: http://zonaelektro.net/motor-dc/. [Accessed 20 Oktober 2017]. 